\title{
Role of Stem Cell Transplantation in Remyelination and Pain Relief after Spinal Cord Injury
}

\section{Sufang Liu ${ }^{1,2}$, Changsheng $\mathrm{Li}^{\mathbf{1}^{1,2}}$, Ying Xing ${ }^{2,3}$ and Feng Tao ${ }^{1 *}$}

${ }^{1}$ Department of Anesthesiology and Critical Care Medicine, Johns Hopkins University School of Medicine, Baltimore, Maryland, USA ${ }^{2}$ Basic Medical College, Zhengzhou University, Zhengzhou, Henan, China

${ }^{3}$ Basic Medical College, Xinxiang Medical University, Xinxiang, Henan, China

According to a report from The National Spinal Cord Injury Statistical Center at the University of Alabama, more than 250,000 Americans have received spinal cord injuries since 2002, and the number increases by 10,000 to 12,000 every year. Spinal cord injury (SCI) can be caused by traumaor disease. Impairment varies according to the location of spinal cord and nerve root damage and may include symptoms from pain to paralysis to incontinence [1]. Research into treatment for SCI includes controlled hypothermia and stem cells, though many treatments have not been studied thoroughly, and very little new research has been implemented in standard care. The actual treatment can vary widely depending on the location and extent of the injury. In many cases, spinal cord injuries require substantial physical therapy and rehabilitation, especially if the patient's injury interferes with activities of daily life.

SCI not only damages neural cell bodies directly at the site of injury but also disrupts descending and ascending axonal pathways that traverse the injury site. The clinical consequences of the injury are often permanent loss of sensory, motor, and autonomic function because the adult mammalian central nervous system (CNS) is unable to regenerate severed axons. When axons within the CNS are transected, they exhibit an initial minimal growth response (sprouting) [2]. Although sprouting can result in some functional recovery [3], extensive axonal regeneration does not occur in the CNS. Compared with nerves of the CNS, peripheral nerves have greater regenerative potential, which can be enhanced by manipulating several growth-promoting elements [4]. Experimental strategies that promote regeneration in peripheral nerves may provide enhancement of CNS axonal growth, and, in some cases, partial functional recoveries have been described [5-7].

Functional loss after SCI results from the initial direct damage of the cord and a secondary cascade of inflammation and excitotoxic damage that considerably worsens the extent of damage and cell loss $[8,9]$. Treatment of spinal cord injuries starts with restraining the spine and controlling inflammation to prevent further damage. Next, growth factors and other molecules are used to stimulate a patient's own stem cells to migrate to the injury and initiate repair by differentiating into neurons. This mechanism intimates that stem cells from other sources may help accelerate the recovery process.

Stem cells are the source of all cells in an organism, and theoretically they have the potential to differentiate into functionally competent cells of different types throughout an individual's whole life. The first publication on isolation of neural stem cells was published in 1994 [10], and the first report on the use of stem cells in SCI was published in 1999 [7]. Stem cell research has demonstrated that cell therapy might repair damage within the CNS [11-13]. Functional defects that occur after SCI are caused by interruption of axonal continuity and/or by focal demyelination as a result of oligodendrocyte degeneration [7]. Of those two types of damage, repairing a site of demyelination appears to be the more realistic goal. Therefore, the primary goal in the use of stem cells in SCI is to replace lost oligodendrocytes with cells that are able to make sufficient myelin for impulse propagation to resume. In support of this objective, a previous report showed that some types of peripheral neuropathic pain from conditions such as multiple sclerosis, GuillainBarre syndrome [14], and diabetic neuropathy [15] are associated with damage to myelin, suggesting that myelinated fibers may modulate pain sensation.

SCI often results in the development of neuropathic pain, which can persist for months or even years after injury. It has been proposed that neuropathic SCI pain may be caused by the presence of an "irritated focus" or "neural pain generator" that is close to the rostral end of the SCI. This possibility was supported by the finding that dorsal horn neurons immediately above the level of SCI demonstrate abnormal spontaneous neuronal activity [16]. More recently, animal and human studies have confirmed that changes occur in the properties of nerve cells close to the site of SCI. These changes include increased responsiveness to peripheral stimulation, an increase in the level of background activity, and prolonged firing after a stimulus [17-19]. Additional studies have demonstrated a number of changes in neurotransmitters and receptors that may lead to an increase in excitation or a reduction in inhibition and result in an alteration of the firing properties of these spinal neurons. Changes have been reported in $N$-methyl-D-aspartate (NMDA) receptors, non-NMDA and metabotropic glutamate receptors, sodium channels, and $\gamma$-aminobutyric acid (GABA)-ergic, opioid, serotonergic, and noradrenergic function. In addition, SCI results in glial activation and increased cytokine and prostaglandin release as well as structural reorganization of inputs in the dorsal horn of the spinal cord [20]. All of these changes can contribute to modulation of pain sensation after SCI.

Chronic neuropathic pain is a common and debilitating consequence of SCI. However, the treatment for SCI pain is not effective. Functional deficits following SCI result from damage to axons, loss of neurons and glia, and demyelination/dysmyelination in the injured spinal cord. Thus, remyelination appears to be one of the most feasible restoration strategies for SCI treatment. Grafting of stem cells is a potential therapy for CNS diseases, including neurodegeneration, ischemia, and SCI. Previous studies have demonstrated that mouse or human embryonic stem (ES) cells can differentiate into oligodendrocytes and produce myelination after spinal transplantation, and that transplantation of ES cells promotes functional recovery after SCI $[7,11]$. Our recent study

*Corresponding author: Feng Tao, Department of Anesthesiology and Critical Care Medicine, Johns Hopkins University School of Medicine, Baltimore, Maryland USA, Tel: 410-614-8059; Fax: 410-614-7711; E-mail: ftao81@jhmi.edu

Received December 31, 2013; Accepted January 09, 2014; Published January 11,2014

Citation: Liu S, Li C, Xing Y, Tao F (2014) Role of Stem Cell Transplantation in Remyelination and Pain Relief after Spinal Cord Injury. J Stem Cell Res Ther 4 158. doi:10.4172/2157-7633.1000158

Copyright: @ 2014 Liu S, et al. This is an open-access article distributed under the terms of the Creative Commons Attribution License, which permits unrestricted use, distribution, and reproduction in any medium, provided the original author and source are credited. 
further demonstrates that spinal transplantation of ES cell-derived oligodendrocyte progenitor cells (OPCs) could be used to enhance myelination in the injured spinal cord and treat SCI-induced chronic neuropathic pain [21].

The use of stem cells to treat SCI has not been thoroughly studied. Current knowledge is too limited to promote stem cell use in standard care. Investigating the properties of stem-cell-derived neurons may help to increase the success rate of stem cell use in the restoration or recovery of function after SCI. Information is needed to improve current treatments. A better understanding of the mechanisms by which stem cells incorporate into the nervous system and become functional would no doubt cast light on physiological and pathological functions of stem cells themselves.

The preceding background section highlights our current understanding of SCI, the resulting pain, and how stem cells can help patients to regain function. However, it also reveals several gaps in our knowledge. Functional loss primarily results from direct SCI and secondary damage; based on our current knowledge, stem cells can contribute to only a partial recovery of functions. The following questions remain: How can the survival rate of injected stem cells be improved? How can the derived neurons be induced to specific neurons? What are the properties of the derived neurons? How do the derived neurons differ from endogenous neurons? Will any of their properties contribute to pain rather than alleviate it? What is their excitatory and inhibitory homeostasis? Given that injury alters the activity of endogenous neurons, how will injury affect the derived neurons? Because so many questions are left to be answered, it is important to study the properties of the stem-cells-derived neurons to help further understand SCI and how stem cells can be used to restore function and reduce pain. Because of the low survival rate of stem cells, researchers have mostly focused on recovery of motor function after transplantation. It is important for future studies to investigate not only motor function recovery, but also reduction of pain after stem cell transplantation.

\section{References}

1. VWHL, DDC, NCC, FSF, MCH (2002) Spinal Cord Medicine: Principles and Practice.

2. Ramon y Cajal S (1991) Degeneration and Regeneration of the Nerve System. Hafner, New York, USA.

3. Weidner N, Ner A, Salimi N, Tuszynski MH (2001) Spontaneous corticospinal axonal plasticity and functional recovery after adult central nervous system injury. Proc Natl Acad Sci U S A 98: 3513-3518.

4. Paul Lu EYS, Tuszynski MH (2003) Stem Cells for Spinal Cord Injury. Neural Stem Cells for brain and spinal cord repair 19.
5. Grill R, Murai K, Blesch A, Gage FH, Tuszynski MH (1997) Cellular delivery of neurotrophin-3 promotes corticospinal axonal growth and partial functional recovery after spinal cord injury. Neurosci 17: 5560-5572.

6. Huang DW, McKerracher L, Braun PE, David S (1999) A therapeutic vaccine approach to stimulate axon regeneration in the adult mammalian spinal cord. Neuron 24: 639-647.

7. McDonald JW, Liu XZ, Qu Y, Liu S, Mickey SK, et al. (1999) Transplanted embryonic stem cells survive, differentiate and promote recovery in injured rat spinal cord. Nat Med 5: 1410-1412.

8. Gimenez y Ribotta M, Privat A (1998) Biological interventions for spinal cord injury. Current opinion in Neurol 11: 647-654.

9. Schwab ME, Bartholdi D (1996) Degeneration and regeneration of axons in the lesioned spinal cord. Physiological reviews 76: 319-370.

10. Morshead CM, Reynolds BA, Craig CG, McBurney MW, Staines WA, et al. (1994) Neural stem cells in the adult mammalian forebrain: a relatively quiescent subpopulation of subependymal cells. Neuron 13: 1071-1082.

11. Martino G, Pluchino S (2006) The therapeutic potential of neural stem cells. Nat Rev Neurosci 7: 395-406.

12. Pfeifer K, Vroemen M, Caioni M, Aigner L, Bogdahn U, et al. (2006) Autologous adult rodent neural progenitor cell transplantation represents a feasible strategy to promote structural repair in the chronically injured spinal cord. Regen Med 1: 255-266.

13. Thuret S, Moon LD, Gage FH (2006) Therapeutic interventions after spinal cord injury. Nat Rev Neurosci 7: 628-643.

14. Pentland B, Donald SM (1994) Pain in the Guillain-Barre syndrome: a clinical review. Pain 59: 159-164.

15. Reeh PW, Kocher L, Jung S (1986) Does neurogenic inflammation alter the sensitivity of unmyelinated nociceptors in the rat? Brain Res 384: 42-50.

16. Loeser JD, Ward AA Jr, White LE Jr (1968) Chronic deafferentation of human spinal cord neurons. J Neurosurg 29: 48-50.

17. Christensen MD, Everhart AW, Pickelman JT, Hulsebosch CE (1996) Mechanical and thermal allodynia in chronic central pain following spinal cord injury. Pain 68: 97-107.

18. Hao JX, Xu XJ, Yu YX, Seiger A, Wiesenfeld-Hallin Z (1992) Transient spinal cord ischemia induces temporary hypersensitivity of dorsal horn wide dynamic range neurons to myelinated, but not unmyelinated, fiber input. J Neurophysiol 68: $384-391$

19. Yezierski RP, Park SH (1993) The mechanosensitivity of spinal sensory neurons following intraspinal injections of quisqualic acid in the rat. Neurosci Lett 157: 115-119.

20. Siddall PJ (2009) Management of neuropathic pain following spinal cord injury: now and in the future. Spinal cord 47: 352-359.

21. Tao F, Li Q, Liu S, Wu H, Skinner J, et al. (2013) Role of neuregulin-1/ErbB signaling in stem cell therapy for spinal cord injury-induced chronic neuropathic pain. Stem Cells 31: 83-91. 